\title{
Bridging the healthcare delivery divide
}

In an ironic bit of healthcare delivery innovation, a district hospital originally designed to treat race groups separately is now inadvertently paving the way for National Health Insurance. One team of doctors and nurses treats all private and public patients equally, using the same facilities.

The 38-bed Clanwilliam Hospital serves a community of some 30000 people of widely diverse incomes across six rural towns nestled between the Cederberg and the West Coast, about 270 kilometres north of Cape Town. Ironically, the way it is designed makes it logistically possible to cater for private and public patients alike, regardless of financial means, with the facility divided into one ward for each category but sharing X-ray equipment, surgical, maternity, paediatric and high-care needs. While the hospital's basic facilities are all too familiar and limited, it's the small healthcare team of two sessional private doctors and two Community Service doctors with shared nursing staff who treat each and every patient that makes it special and worth emulating in South Africa's hugely under-staffed public healthcare system now being comprehensively re-engineered.

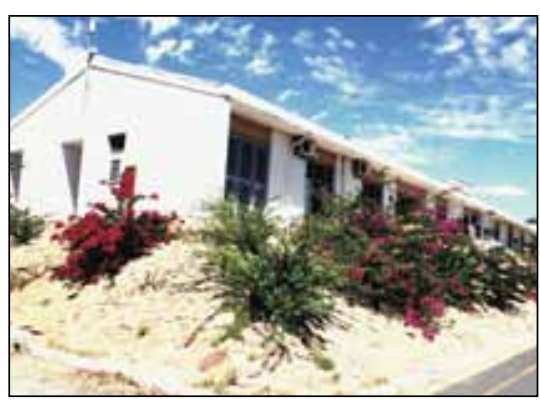

Clanwilliam Hospital.

All Clanwilliam Hospital's state patients - the highest volume of cases - are seen by clinical nurses at the primary healthcare clinic. Here the communal TB and HIV/AIDS treatment and awareness, pre- and antenatal care, immunisation and gastroenteritis care and/or campaigns are run. Clinic Head, Sister Andriëtte Koegelenberg, estimates that they see some 300 - 500 patients a week, about $10 \%$ of whom they are 'supposed to' refer to the doctors, but it doesn't always work that way.

\section{Continuity of treatment the key}

'Some days you hardly refer anyone and there are days that you refer more than half your patients, she says candidly. When the doctors do their rounds at the clinic they consult these referrals, admitting them to hospital as necessary. Those with medical aid or the means to pay end up at the private rooms of the two sessional doctors, Herman Uys and Frikkie Strauss, the latter who doubles up as the Clanwilliam Hospital's Superintendent. The GP duo are the only district-level-qualified act in town, so they conduct all surgical procedures and keep all the necessary hospital admission forms in their consulting rooms. Explains Strauss, 'If we book a patient in, they remain our responsibility - it's our moral and ethical obligation to make sure they get the care they need. The same rule applies to every other doctor in town; whoever they admit to the hospital, regardless of their financial situation, remains their responsibility. Strauss believes this continuity of treatment by the town's permanent doctors, regardless of economic status, is what contributes to making the district hospital such a success story. 'We take ownership of the town's health. We know all the patients and are familiar with their cases from consultation to treatment, because we examined them in the first place. When I admit a patient into hospital I don't hand them over to a different doctor and say "now it's your problem" I treat that patient myself. They are my responsibility, adds Strauss.

The sessional duo use an extensive network of specialists in Cape Town and refer patients to the better resourced hospitals as necessary. Consultants visit Clanwilliam Hospital once a month, covering obstetrics, orthopaedics, gynaecology and optometry, among others. There is a well-circulated and structured plan so patients know when their particular specialist will be available. Emergency cases

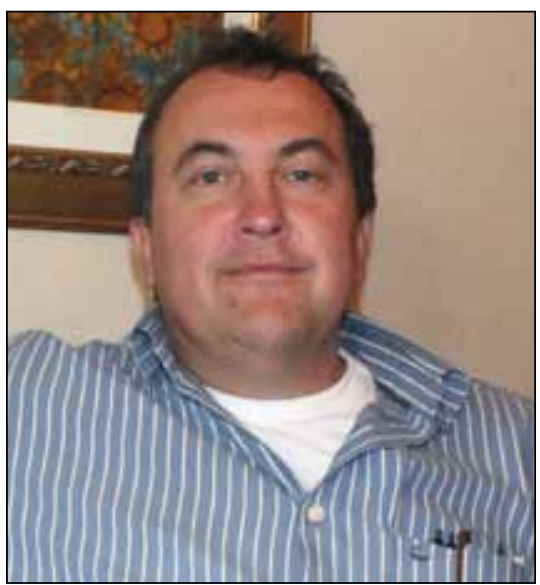

Dr Frikkie Strauss, Clanwilliam Hospital Superintendent. are treated equally, the local ambulance or medivac helicopter rushing them to Cape Town on a priority triage basis.

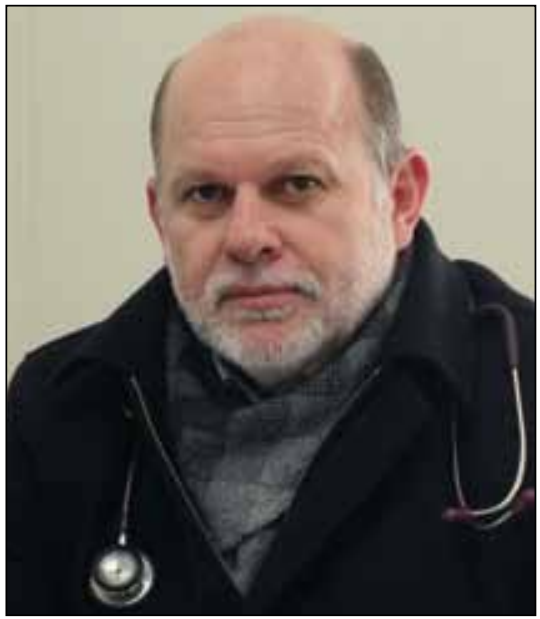

Dr Herman Uys.

Hospital Matron Marianna van den Heever has a pragmatic system for equitable patient care between the two wards (the much smaller Ward A can be distinguished as being for private patients by its television set and remote control - not much else). When there are no private patients, all her staff focus on the much larger Ward B, and when there is an emergency, such as a serious car accident, Matron Van den Heever and all her nurses come together in the casualty unit to treat all victims.

\section{Keeping hospital \\ finances healthy}

Until three years ago, the hospital was provincially aided. The state contributed $90 \%$ of the funds and the facility used the fees paid by private patients to generate the rest. 'But during this time our staff members got no state benefits (like a state pension), so that was part of the motivation for becoming a provincial hospital, which means we are now completely state funded,' says Strauss.

Despite receiving full funding from government, the hospital still uses private medical fees to bolster its coffers. 'Thanks to the private fees, this hospital has reached its budget targets long before the end of the financial year. Our bank balance is looking healthy, which is very good because now we can look at buying additional equipment, or replacing older equipment,' he says. Essentially, the hospital operates with two balance sheets. One of these covers state funding, while the second revolves around income sourced from private patient fees. Juggling a dual-income system like this within 


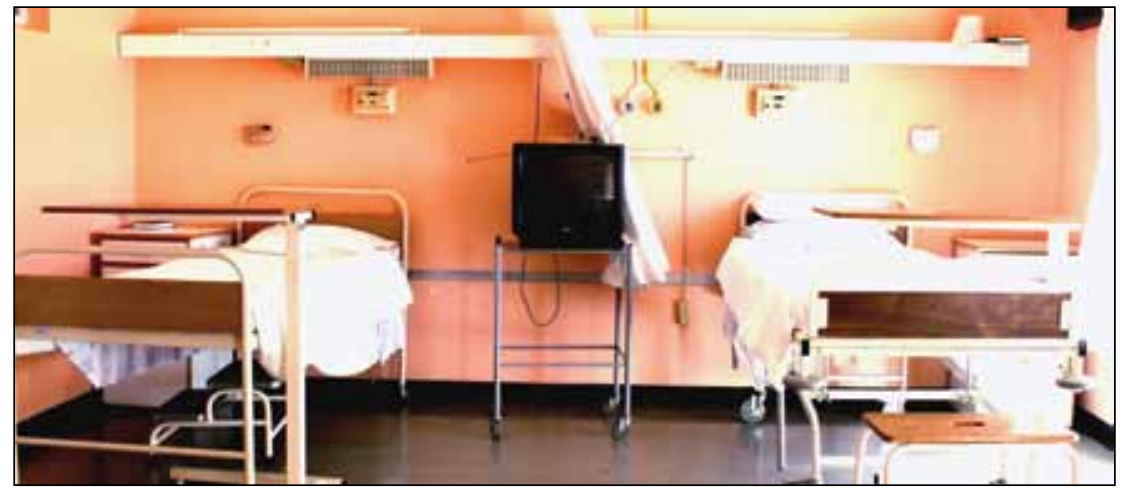

The 'private' wards at Clanwilliam Hospital.

the hospital's own structures could easily open the door for fraud, but to prevent this the hospital's finances are tightly controlled by an independent auditing committee, many of whose members have with no ties to the facility at all. They meet once a month in Vredendal, about $90 \mathrm{~km}$ from Clanwilliam.

\section{Independent oversight}

'This oversight committee is our biggest defence against fraud. I'm not saying we don't trust anyone we work with - on the contrary, we operate so effectively because of trust between staff members. Should there ever be anyone who wants to try the system they would have to get around the committee, and that's never going to be easy', says Strauss. The controls in place at the hospital mean the committee needs to approve any spending, and no stock can be ordered without its green light. Because of the committee's independence, it is able to exercise strict controls over the money allocated to the facility. While the system has many benefits, it also has some downfalls. Proper stock management is essential because financial meetings only take place once a month. 'You must make sure you have enough of the basics to see you through until new stock arrives. Also, you can't run out of surgical gloves a week after the committee has met, because then you sit with a huge problem,' says Van den Heever. 'The nurses here are very well trained in the procedures that need to be followed when it comes to stock ordering. They are also very good in watching stock levels, and each section head has the responsibility to make sure their section has everything it needs, and that stock has been ordered properly.

There is leeway for emergencies, like a breakdown of essential surgical equipment. 'In a situation like that, the financial committee will call an emergency meeting to get funding approved. This has happened in the past and I am sure it will happen again in the future, but these emergency meetings will only take place in serious cases. We like clerical errors - someone forgetting to order surgical swabs, for example. Those are situations we have to deal with in-house, like paying for the order out of petty cash, and then we have to explain it to the committee at the next meeting, explains Strauss. Tight financial control and dedicated, empathetic staff are two very large pieces in the hospital's puzzle of success, but they would mean nothing without a third, equally important element: Excellent hospital management.

\section{First-class management - at the heart of success}

At the core of the hospital lies a team of administration staff who manage shift rosters, daily finances, patient files, admissions, discharges and the facility's human resources. 'This is truly where the strength of the hospital lies. Without this team, we wouldn't be able to function. They ensure that all patient documentation is in order, that stock requisitions are filed with the financial committee on time, that there are enough nurses on duty and that anyone who walks through the door is taken care of, says Van den Heever.

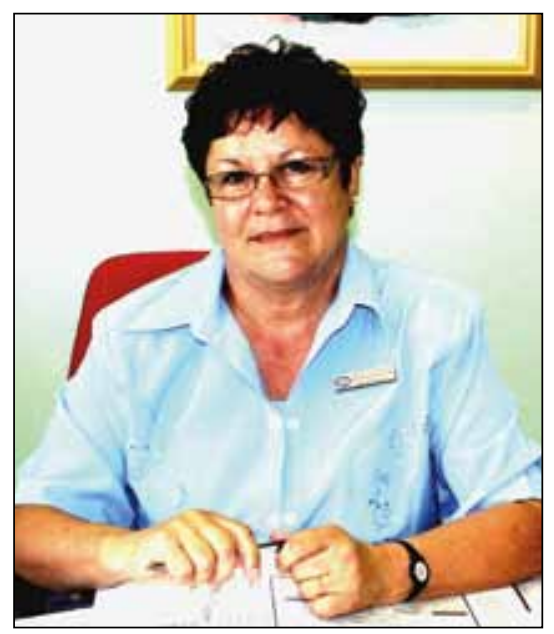

Matron Marianna van den Heever. can't call an emergency meeting for mishaps
So what sets this administration team apart from those found at every other state hospital in the country - and why does this hospital function so well, when so many others battle? Van den Heever believes collective experience plays a great part. 'Some of the people in our admin office have been here for more than 20 years. Not only are they familiar with the community, they also know the hospital, its systems and procedures like the back of their hands. This is not a job for them, this is a service to their community and they do it without question,' she says.

'Most importantly though, these people are management professionals. We are medical professionals, they are management professionals - we take care of our patients, they take care of the business side of things. There is a clear difference, we don't have nurses trying to run the hospital's books, and we don't have admin staff in the surgical wards. It's that simple.'

In a philosophical moment, Strauss muses: 'Can you imagine what the situation would be like if every single private practice doctor in South Africa, from your everyday GP to your most highly specialised neurosurgeon, was to dedicate just two hours per day to patients at state facilities?'

He fervently believes the sessional doctor approach gives doctors the freedom to run their private practices while giving them a channel through which they can help a broader slice of society.

Could it really be that simple? Perhaps, but a collective act of will and mutual trust across the private/public divide, accompanied by a general outbreak of ubuntu, would certainly help.

Dr Saul Kornik, CEO of Africa Health Placements, the non-profit NGO recruiting local and foreign healthcare workers, said using locally trained doctors alone would not fix the HR shortage and equity dilemmas. Additional methods were desperately required. The 'scarce and mobile' cadre of 3000 foreign-qualified doctors currently working in South Africa (10\% of our medical workforce) needed substantial boosting via more efficient registration which would keep the country globally recruitment-competitive. He cited the relatively well-resourced UK where more than a third of doctors were foreign qualified.

JP and Tracy du Plessis for Africa Health Placements, edited by Retha Grobbelaar and Chris Bateman

\section{chrisb@hmpg.co.za}

S Afr Med J 2012;102(9):727-728.

DOI:10.7196/SAMJ.6187 